\title{
Pensamiento y paradigma socio-crítico como referente para unas finanzas más humanas
}

\section{Socio-critical thinking as a reference for more-human finances}

\author{
Mario Fernando Chacón Sánchez ${ }^{1}$ \\ DOI: 10.29151/hojasyhablas.n18a5
}

\section{Resumen}

Este artículo es resultado del proyecto de investigación titulado "Alternativas transformadoras en Finanzas y Negocios Internacionales a partir de teorías socio-críticas. Un aporte desde la Unimonserrate", el cual recoge discusiones de las ciencias sociales y la filosofía, y cuestiona formas aparentemente establecidas en las finanzas como la acumulación de capital exclusiva para grandes inversionistas. Así mismo, se repasa la teoría crítica, el posestructuralismo y el pensamiento de(s)colonial latinoamericano. La metodología empleada fue el análisis documental de textos de autores representativos de la Escuela de Fráncfort, el Pensamiento De(s)colonial latinoamericano y los autores Pierre Bourdieu y Michael Foucault, buscando específicamente aquellos argumentos que tuvieran potencial para la crítica de la actividad financiera con posibilidad de argumentación propositiva, a partir de la elaboración de fichas de lectura.

Palabras clave: Paradigma socio-crítico; Finanzas; Escuela de Fráncfort; Posestructuralismo; Colonialidad.

\begin{abstract}
This article is a result of the "Transformative alternatives in Finance and International Business from socio-critical theories. A contribution from the Unimonserrate" research project, which includes social sciences and philosophy debates, and questions the understanding of finance such as the accumulation of capital. Likewise, critical theory, post-structuralism and decolonial thinking are reviewed. The methodology used was the documentary analysis by representative thinkers of the Frankfurt School, Decolonial Thinking and authors as Pierre Bourdieu and Michael Foucault specifically, looking for arguments that may be potential for the criticism of financial activity.

Keywords: Socio-critical thinking; finances; Frankfurt School; Postestructuralism; Coloniality.

${ }^{1}$ Licenciado en Ciencias Sociales, Magíster en Análisis de Problemas Políticos, Económicos e Internacionales Contemporáneos, Candidato a Doctor en Educación e integrante del Grupo de Investigación GENEME. E-mail mfchacon@unimonserrate.edu.co 


\section{Introducción}

Este trabajo explora las posibilidades de unas finanzas desde los referentes del paradigma crítico, repasando algunas escuelas de pensamiento de las ciencias sociales y la filosofía que pueden ofrecer alternativas para hacer de esta actividad económica una actividad más humana, teniendo en cuenta que se trata de dilucidar puntos de referencia que permitan posibles salidas ante la situación de la creciente pauperización y el contraste con la acumulación y concentración de la riqueza, en lo que las finanzas tienen mucho que ver como herramienta de los más poderosos.

En tanto que, la crítica como pensamiento $y$ actitud frente al mundo, no se reduce a la característica exclusiva de tal o cual escuela de pensamiento, se parte de la posibilidad de cuestionar el fundamento de los conocimientos (Zuleta, 2005), que a su vez engendran definiciones, normas y procedimientos, convirtiéndose en la "realidad" y llegando a presentarse como incuestionables y difíciles de modificar, siendo la crítica una pregunta por el presente y de cómo se puede transformar (Foucault, 1988; Castro-Gómez, 2013).

En ese orden de ideas, se presentan planteamientos de tres enfoques reconocidos en la crítica a las sociedades contemporáneas, tales como la teoría crítica, el posestructuralismo y el pensamiento de(s)colonial latinoamericano. En cada sección se realiza una propuesta que se desprende de la lógica de cada uno de estos esquemas de pensamiento, tratando de aprovechar el matiz particular de cada énfasis crítico, que va desde el rechazo total de la actividad financiera, hasta diferentes estrategias para moderar y socializar las ganancias de las finanzas.

Como parte la naturaleza de esta investigación, la propuesta se presenta en términos de derroteros a ser debatidos y llevados a las prácticas sociales, siendo conscientes que como toda propuesta es resultado de apreciaciones y moti- vaciones subjetivas del autor, y que seguramente podrían haber sido concebidas de maneras distintas según quien realizara la investigación. En el fondo, se trata de mostrar que cualquier actividad puede ser orientada de forma humana si se tiene la voluntad, pues por más especializada y lejana al público lego, no existe ningún argumento para defender que las finanzas, ni ningún otro conocimiento, tengan porqué ser empleados para aumentar la pobreza del mundo.

A partir de la revisión documental realizada, se entiende que el pensamiento crítico no es posesión exclusiva de un enfoque investigativo determinado, sino que es una facultad del pensamiento humano, cuando se pregunta por las condiciones del presente y el origen de las cosas que hacemos, cómo las hacemos y por qué. A esto apunta $\mathrm{Mi}$ chael Foucault cuando sostiene que "necesitamos conocer las condiciones históricas que motivan nuestra conceptualización. Necesitamos una conciencia histórica de nuestra circunstancia actual" (Foucault, 1988, p. 4).

Esta actitud de cuestionamiento implica, por lo menos, dos planos de abordaje: el plano del pensamiento y el plano de la acción, que pueden apreciarse tanto en la acción subjetiva cuando un ser humano cuestiona su vida cotidiana y hace algo para salir de las condiciones que considera injustas, pero también en el nivel científico en la producción de teorías críticas y generación de conocimiento emancipatorio en investigaciones que buscan transformar la realidad social. Por ello, cuando se hace referencia en este trabajo a la perspectiva crítica o más bien, a las perspectivas críticas, no se limita solamente al plano del pensamiento o de la acción, pues se reconoce que estos dos planos están ligados y que se complementan mutuamente, tal como lo presentó Marx en la tesis número XI sobre Feuerbach, que dice "los filósofos no han hecho más que interpretar de diversos modos el mundo, pero de lo que se trata es de transformarlo" (Marx, 1845, p. 2). 
Desde entonces, este postulado ha sido el fundamento de pensar y actuar crítico en las ciencias sociales, lo que no invalida las intenciones meramente teóricas que son referente de la acción, ni las acciones transformadoras que puedan parecer carentes de sustento teórico, ya que sería como decir que la teoría crítica de la Escuela de Fráncfort o la teoría de Foucault no son críticas, porque no llevan de la mano acciones sociales concretas, cuando por el contrario son pensamiento potenciador que cuestiona las bases de las sociedades contemporáneas y posibilitan un fundamento riguroso para la comprensión y para la acción. O en el otro plano, afirmar que una acción social de reivindicación de derechos no es crítica porque carece de una teoría científica explicitada cuando, por el contrario, está transformando el mundo sin más.

Esto lleva a comprender que las teorías críticas, entre las que se pueden mencionar el marxismo, la teoría crítica, la teoría de Foucault y el pensamiento crítico latinoamericano, entre otras, son referentes ineludibles al buscar inspiración para unas finanzas desde el paradigma socio-crítico. Igualmente, el mismo paradigma socio-crítico, que se basa en un enfoque investigativo participativo, tomando referentes en Freire, y en general en el trabajo comunitario para generar conocimiento que transforma, son el fin último de la actitud crítica. Los dos planos no se anulan, se complementan.

Por lo anterior, aquí no se trata de dar cuenta de manera extensa y completa de todas las teorías, lo que sería ambicioso, humanamente imposible y carente de originalidad, pues lo que se quiere es invitar a la apertura del pensamiento y acción de las finanzas, evitando el encerramiento en la actividad excesivamente tecnocrática que termina posicionando un conocimiento especializado para enriquecer a los más ricos. Es en eso justamente que espero que las y los lectores me puedan acompañar, esperando que ojalá se hagan nuevas investigaciones para ampliar o completar la propuesta modesta de este documento, no tanto en enfrascarse en lo docto del manejo de la teoría, sino en la apertura de pensamiento desde las finanzas hacia lo social.

\section{¡Qué mueran las finanzas! Marx y la Escuela de Fráncfort como referentes para unas finanzas con perspectiva crítica}

Karl Marx es, sin duda, uno de los autores más controversiales de la historia del pensamiento humano, puesto que cuestiona la manera como se ha establecido la sociedad contemporánea desde el punto de vista de la denuncia de la explotación del hombre por el hombre, una crítica frontal al capitalismo, siendo inspirador de movimientos sociales y movimientos armados a lo largo del mundo, e identificado como uno de los tres maestros de la sospecha, según el historiador francés Paul Ricoeur (1970, p. 32), junto con Nietzsche y Freud. Estos tres pensadores tratan de desmitificar el orden de las cosas en las sociedades contemporáneas, generando tempranamente una comprensión crítica sobre los excesos del capitalismo, la industrialización y la modernidad. La teoría de Marx terminó materializada además en los sistemas socialistas cuestionados por el autoritarismo y la anulación de las subjetividades, por lo que los teóricos de la Escuela de Fráncfort retomaron algunos planteamientos de Marx, matizando a partir del reconocimiento de las problemáticas percibidas del capitalismo y del socialismo. A continuación, se repasan brevemente algunas de las ideas de Marx y de la Teoría crítica de la Escuela de Fráncfort de utilidad en la apertura de las finanzas para posibilitarla como una actividad más humana.

Teoría de Marx para la crítica de las finanzas

Un referente obligado para el pensamiento y la acción crítica es Marx, quien propone una comprensión de la historia desde el materialismo dialéctico, en donde la lucha de contrarios se manifiesta en la lucha de clases como motor de 
la historia (Marx y Engels, 1848). En el capitalismo, se trata de poner de manifiesto la relación de explotación entre burguesía, clase poseedora del capital y proletariado, clase que solamente posee su propia fuerza laboral. Esta relación está encubierta por medio del salario, pues se hace pensar que es aceptable que los trabajadores reciban un precio por su trabajo, cuando la riqueza, como aumento incesante del capital, es resultado de la transformación que implica la mano de obra sobre las materias primas. La riqueza es socialmente producida, pero es apropiada individualmente, solamente por los dueños del capital, y si todos han participado de la producción deberían también participar de la ganancia en igual medida (Marx, 1867, pp. 651-660).

Al llevar este planteamiento como referente de unas finanzas críticas, habría que decir que las finanzas como actividad económica deberían desaparecer, puesto que se basan en una sofisticación de la apropiación de ganancias por parte de quien tiene el conocimiento y el capital para entrar en el juego financiero, que por lo demás, es una actividad parasitaria en cuanto a que no genera producción en la economía real, sino que basa su actividad en la especulación de los mercados, denominado como proceso de financiarización de la economía (Medialdea y Sanabria, 2013, pp. 198199), por lo que sería considerada una aberración del capitalismo, pues un rendimiento jugoso en un lugar, en otro se está generando pobreza.

De otro lado, podría plantearse que, si bien la actividad financiera genera mayor acumulación de riqueza en pocas manos con la consecuencia de aumento de la pobreza, la actividad en sí misma podría orientarse hacia un reparto social de las ganancias, democratizando las finanzas y permitiendo que todas las comunidades puedan participar de la actividad financiera y de sus rendimientos.

\section{Escuela de Fráncfort para unas finanzas críticas ${ }^{2}$}

La teoría marxista está de fondo como punto de referencia en diversos enfoques críticos, tal como en la teoría crítica de la Escuela de Fráncfort, el colectivo de intelectuales alemanes ${ }^{3}$ de mediados del siglo XX, quienes percibían los sistemas políticos y económicos imperantes, capitalismo y socialismo, como cargados de excesos, totalitarismo y falsa libertad.

Con el desarrollo del sistema económico, en el que el dominio de grupos privados sobre el aparato productivo divide y separa a los hombres, la autoconservación retenida idéntica por la razón, es decir, el instinto objetivado del individuo burgués, se reveló como fuerza natural destructora, imposible ya de separar de la autodestrucción. La una se convirtió confusamente en la otra. La razón pura devino antirrazón, procedimiento impecable y sin contenido. Pero aquella utopía que anunciaba la reconciliación de naturaleza y sujeto salió, junto con la vanguardia revolucionaria, de su escondrijo en la filosofía alemana, irracional y racional a la vez, como idea de la asociación de hombres libres y atrajo hacia sí todo el furor de la ratio (Horkheimer \& Adorno, 1994, pp. 137-138).

\footnotetext{
${ }^{2}$ Los planteamientos de este apartado sobre Escuela de Fráncfort retoman algunas de las ideas esbozadas en la ponencia presentada en el Congreso Internacional de Investigación en Ciencias Administrativas, ACACIA, en Puerto Vallarta, mayo de 2017, ver Chacón y Urrego (2017).

${ }^{3}$ La primera generación de autores de la Escuela de Fráncfort incluye a Max Horkheimer, Theodore Adorno y Herbert Marcuse. La segunda principalmente a Jürgen Habermas y la tercera a Axel Honneth, entre otros (Sampaio, 2009).
} 
Particularmente, los teóricos de la Escuela de Fráncfort de la primera generación encontraron que el conocimiento científico, como máxima expresión de la razón, habría terminado por ser un instrumento del sistema, pues se presenta como conocimiento neutral, pero termina encubriendo la explotación del capitalismo, esto es como razón instrumental, de manera que en el capitalismo, solamente merece la pena existir lo que pueda contribuir con la productividad del sistema, siendo el conocimiento científico presa de este requerimiento, pero más aún una herramienta.

Las funciones ejercidas otrora por la razón objetiva, por la religión o por la metafísica han sido adoptadas por los mecanismos cosificantes del aparato económico anónimo. Lo que determina la colocabilidad de la mercancía comercial es el precio que se paga en el mercado y así se determina también la productividad de una forma específica de trabajo. Se estigmatiza como carentes de sentido o superfluas, como lujo, a las actividades que no son útiles o no contribuyen, como en tiempos de guerra, al mantenimiento y la seguridad de las condiciones generales para que prospere la industria. El trabajo productivo, ya sea manual o intelectual, se ha vuelto honorable, de hecho, se ha convertido en la única manera aceptada de pasar la vida, y toda ocupación, la persecución de todo objetivo que finalmente arroja algún ingreso, es designada como productiva...El pensamiento moderno ha intentado convertir este modo de ver las cosas en una filosofía, tal como la presenta el pragmatismo. Constituye el núcleo de esta filosofía la opinión de que una idea, un concepto o una teoría no son más que un esquema o plan de acción, y de que por tanto la verdad no es sino el éxito de la idea (Horkheimer, 1973, p. 30).

Según Marcuse (1985), se llega a una sociedad unidimensional en la que todo se reduce a la productividad, hasta lo más revolucionario termina por ser productivo, quedando inevitablemente dentro del sistema, como sociedades que se presentan como democráticas, pero en el fondo son totalitarias, ya que nada escapa al consumismo.
Por su parte, Horkheimer (1973) es pesimista, por cuanto no parece haber salida a la situación a la que nos ha llevado el exceso de razón como resultado del proyecto ilustrado, ante lo que propone pensar independiente, en oposición con la razón instrumental:

En una palabra, para bien y para mal, somos los herederos de la Ilustración y del progreso técnico. Oponerse a ellos mediante una regresión a etapas primitivas no constituye un paliativo para la crisis permanente que han provocado. Tales salidas conducen, por el contrario, de formas históricamente racionales a formas extremadamente bárbaras del dominio social. El único modo de socorrer a la naturaleza consiste en liberar de sus cadenas a su aparente adversario, el pensar independiente (p. 79).

Siguiendo los planteamientos de la escuela de Fráncfort hacia las finanzas, se encuentra que esta actividad económica se basa en la aplicación de un conocimiento experto, que además implica la posesión de grandes capitales para que los movimientos financieros tengan sentido, demostrando una alianza entre la lógica del capitalismo y el conocimiento como razón instrumental, puesto que se requiere de capital para invertir en finanzas pero con base en un conocimiento de las variables del mercado para saber en qué momento se debe invertir sobre cuáles productos financieros, como se hace cotidianamente en las bolsas de valores. El conocimiento experto de las finanzas, que mezcla economía con matemática financiera, pero también identificación de las señales políticas y ambientales, es un conocimiento híper especializado, al que difícilmente las personas del común pueden acceder, también porque de nada sirve tenerlo si no se cuenta con el capital para invertir. Luego, es un conocimiento cerrado principalmente al servicio de los grandes inversionistas, que por lo demás se hace pasar como conocimiento neutral, cuando se está empleando conscientemente para la acumulación y concentración de riqueza, es decir, se corresponde con la definición de razón instrumental. 
Desde los planteamientos de la Escuela de Fráncfort se pediría pensar independiente (Horkheimer, 1973), lo que implicaría permitir que las comunidades puedan tener acceso a la actividad financiera, que participen de la manera como se distribuye la riqueza en el mundo, de manera que no sean actividades exclusivas de los grandes inversionistas. Sin embargo, no se trataría de que todos se conviertan en capitalistas, además porque poder contar con un excedente económico para invertir no resulta tan sencillo para millones de personas que luchan por obtener el sustento diario. Así las cosas, lo que se requiere es pensar independiente y posibilitar la salida de la razón instrumental en la actividad financiera, pero en los dos aspectos: conocimiento especializado en finanzas y capital para invertir.

Lo anterior, se puede posibilitar en el trabajo con las comunidades desde un enfoque participativo y crítico, en el que expertos y expertas en finanzas puedan acompañar las iniciativas comunitarias para hacer parte de la actividad económica que genera mayores ganancias en la actualidad, tratando de compensar la pobreza que la actividad financiera ha disparado en el mundo, por un reparto más equitativo de la riqueza a partir de la democratización de la actividad financiera desde un pensar independiente del conocimiento especializado de las finanzas.

Así las cosas, este enfoque crítico reconoce la importancia de la estructura económica en lo que las finanzas han contribuido negativamente a generar un reparto inequitativo de la riqueza, como una estrategia más sofisticada de explotación y excesos de la razón que terminan instrumentalizando unos conocimientos técnicos, como son los de las finanzas, para ahondar en la acumulación de riqueza en pocas manos, debido a la especial- ización del conocimiento y a las posibilidades de participar de esta actividad económica solamente a quienes tienen grandes capitales especulativos.

\section{Posestructuralismo como referente crítico para la actividad financiera}

Durante décadas las explicaciones de las ciencias sociales sobre el mundo giraron alrededor de dos enfoques que, a pesar de ser opuestos en su sentido, proponían comprender a la sociedad como estructura, desde la esquina crítica, el marxismo y en el otro lado, el funcionalismo, lo que generó la necesidad de buscar la recuperación del sujeto que tendía a ser olvidado en estas dos escuelas ${ }^{4}$. Así, toman fuerza las escuelas hermenéuticas y subjetivistas que buscan entender el sentido de las acciones humanas y la comprensión de los universos simbólicos. En esta sección se optó por tomar aquellos enfoques que sin perder lo crítico del estructuralismo, que reconoce los determinismos a los que los seres humanos estamos abocados, se esfuerzan por recuperar la fuerza del sujeto como potenciador del cambio social, escogiendo las dos -que a juicio propio- ofrecen mayor potencial de transformación y que pueden ser consideradas igualmente dentro del paradigma crítico.

Cabe resaltar que, la denominación de posestructuralismo fue rechazada por el mismo Foucault, quien prefería ser reconocido como estructuralista, pero a pesar de ello, es una apelación que indica para la teoría sociológica y el trabajo riguroso para reconciliar sujeto y estructura. Lo que hace parte del giro posestructuralista en ciencias sociales, con autores como Foucault, Deleuze, Derrida y Guattari, emplea diversas disciplinas para romper con la referencia economicista a la estructura y amplía el reconocimiento de otros determinantes como el lenguaje, el poder, el de-

\footnotetext{
${ }^{4}$ Para ser justos con estos enfoques, se puede afirmar que la referencia a la clase social ya de hecho plantea el reconocimiento de los seres humanos, asimismo, la versión gramsciana del marxismo que se detiene en la cultura y en el papel de los intelectuales. Por el lado del funcionalismo, el sujeto aparece en el interaccionismo simbólico, pero aquí de lo que se trata es de mostrar la novedad de otras perspectivas críticas más propias de la segunda mitad del siglo XX.
} 
seo (Rifa, 2003), para entender la sujeción del sujeto de manera mucho más compleja además de lo económico. En el caso de Pierre Bourdieu, se recoge la tradición sociológica para salir de la referencia extremista del estructuralismo o del subjetivismo.

\section{Foucault para entender las finanzas}

Foucault es uno de los autores más influyentes de la segunda mitad del siglo XX y hasta la actualidad, pues sus planteamientos alcanzan a soslayar las bases de las sociedades actuales, siendo una poderosa herramienta de pensamiento crítico. Para Foucault, su programa de investigación está dado por el interés de entender cómo el sujeto se encuentra sujetado, por la estructura en la que está inmerso, pero a la vez también por sí mismo. No obstante, en su análisis no se plantea un esquema de explotación como lo hace el marxismo, sino que se concibe una estructura compleja conformada por tres estructuras, resultado de tres tipos de relaciones, como lo son las relaciones de producción, las de comunicación y las relaciones de poder. Estas tres están vinculadas íntimamente por lo que no resulta tan sencillo, ni tan completo de separar y comprender el mundo social desde una sola de ellas:

No debe confundirse entonces las relaciones de poder, las relaciones de comunicación y las capacidades objetivas. Ello no quiere decir que se trate de tres dominios separados, ni que de un lado exista el campo de las cosas, de la técnica perfeccionada, del trabajo y de la transformación de lo real; por otro lado, el de los signos, la comunicación, la reciprocidad y la producción de significado, y finalmente, el da la dominación de los medios de coacción, de desigualdad y de la acción de los hombres sobre otros hombres. Se trata de tres tipos de relaciones, que de hecho siempre se traslapan, se apoyan recíprocamente y se utilizan mutuamente como instrumentos. La aplicación de las capacidades objetivas, en sus formas más elementales, implica relaciones de comunicación (ya sea bajo la forma de información previamente adquirida o de trabajo compartido); también está vinculada a relaciones de poder (ya sea que consistan en tareas obligatorias, en gestos impuestos por tradición o por aprendizaje, en subdivisiones y en la distribución más o menos obligatoria del trabajo). Las relaciones de comunicación implican actividades terminadas (aunque sólo sea la puerta en juego correcta de elementos de significado) $\mathrm{y}$, en virtud de la modificación del campo de información entre parejas, producen efectos de poder. En cuanto a las relaciones de poder mismas, en una parte fundamental se ejercen mediante la producción y el intercambio de signos; difícilmente se les puede disociar de las actividades terminadas, ya sean las que permiten ejercer el poder (como las técnicas de entrenamiento, los procesos de dominación, los medios mediante los cuales se obtiene la obediencia) o las que recurren a relaciones de poder con el fin de desarrollar su potencial (la división del trabajo y la jerarquía de tareas). Desde luego, la coordinación entre estos tres tipos de relaciones no es ni uniforme ni constante. (Foucault, 1988, pp. 12-13)

Así las cosas, los sujetos están sujetados por sus relaciones de producción, pero también por la comunicación, por la manera como se definen las cosas, pues al nombrar y clasificar, y con ello separar, se establece la noción de lo que es el sujeto y las cosas, con tal fuerza en los discursos que reglamentan el mundo tales como el discurso jurídico y el científico. El sujeto queda sujetado a las definiciones, siendo el discurso toda una estructura que crea al mundo de forma caótica, puesto que no obedece a un orden preestablecido o a la actuación maquiavélica de algún actor social, sino que es resultado de cruces de otros elementos discursivos, que al encontrarse en puntos nodales le dan forma al discurso que circula y se hace generalizado y aceptable (Foucault, 1992). No es una lógica formal, ni una lógica dialéctica: es caos, impredecible y casi indefinible. El discurso puede tomar caminos y formas inesperados, en el entrecruce de variadas líneas discursivas, que pueden provenir de diferentes campos del saber. 
La tercera estructura de relaciones se refiera a las relaciones de poder, que según el autor están presentes en toda relación social, pero que en las sociedades modernas se pueden estudiar a través de la capacidad que tiene el Estado de incidir en poblaciones enteras, llegando a definir lo que se dice y con ello lo que se hace. Solamente que, las relaciones de poder no son exclusivas del Estado, sino que se presentan como gobierno en todas las relaciones sociales, cuando se confronta de manera agonística y no antagónica, entre sujetos que se consideran libres (Foucault, 1988; Deleuze, 2015).

Para Foucault (1988), no son dominios separados sino que están auto-implicados, por lo que el sujeto está sujetado de manera múltiple y compleja, a lo productivo, a la comunicación y lenguaje y a las relaciones de poder, por lo que de fondo está la pregunta si el sujeto puede ser libre, de escapar a lo que dicen que es, a lo que se espera de lo que dicen que es, a las relaciones productivas, a los esquemas del poder del Estado, pero también, si el sujeto puede escapar a ser sujetado por las condiciones de las relaciones de poder con quienes se relaciona (Deleuze, 2015).

De acuerdo con lo anterior, para unas finanzas desde una perspectiva crítica desde el enfoque de Foucault sería necesario indagar por la manera como se presentan las tres estructuras de relaciones, producción, poder y comunicación, para con ello posibilitar una ruptura de la sujeción que esta actividad económica produce, con énfasis en las relaciones de producción, comunicación y de poder. Así, lo que se propone es una revisión de la discursividad de las finanzas, como parte de la estructura de las relaciones de comunicación, que posiciona esta actividad como necesaria para los Estados, hasta el punto de no poder concebir una política económica sólida que no contenga aspectos como la inversión extranjera directa, lo que lleva a que se tengan que tomar medidas para obtener altas calificaciones por las entidades que miden el riesgo financiero mundial, so pena de no contar con la aprobación para préstamos interna- cionales o generar el rechazo de los inversionistas mundiales, lo que significaría una iliquidez en el mediano plazo, a pesar de que se sabe que las implicaciones de la dependencia de la inversión extranjera termina siendo nociva para una economía nacional, pues no solamente se trata de abandonar los sectores productivos de la economía real, sino que el retiro repentino de capitales extranjeros puede llevar a profundas crisis, sin contar con que las medidas necesarias para ser percibidas por la globalización como una sociedad apetecida para invertir, incluye reducción de los salarios (o aumento inferior al costo de vida), austeridad en la inversión social y en general, dependencia de frente a los derroteros internacionales (Stiglitz, 2002).

Más que una respuesta contundente, lo que se encuentra es la necesidad de realizar investigaciones sobre la discursividad de las finanzas desde el enfoque de Foucault como genealogía, identificando cómo se logra la restricción del lenguaje técnico financiero que no todos pueden hablar por su nivel de especialidad; rastreando cómo se consolida la voluntad de verdad en el discurso financiero que se presenta como deseable, suave, universal y necesario; en la historicidad del discurso financiero reconociendo los acontecimientos discursivos que le dan forma, desde el azar, la discontinuidad y la materialidad (Foucault, 1992), a partir de la elección de un corpus documental que posibilite dichas indagaciones. Por último, sobre el poder ejercido de manera reticular entre sujetos, se puede indagar por las prácticas financieras que se ejercen en micro niveles, como los agiotistas callejeros, en Colombia como préstamos gota a gota, para analizar las relaciones de poder que se pueden establecer. 
La teoría de los campos de Bourdieu y la crítica a la actividad financiera

El sociólogo francés Pierre Bourdieu intenta superar lo que denomina falsas dicotomías de las ciencias sociales, entre estructuralismo y subjetivismo, teoría y práctica, razón e inconsciente, cuantitativo y cualitativo, en una teoría que se fue construyendo a lo largo de varias décadas, y en la que pasó de un pesimismo basado en el determinismo de la reproducción cultural ${ }^{5}$, a una teoría del cambio social de tipo crítico ${ }^{6}$. Este microcosmos social se puede estudiar como campo, a la manera de campo científico, campo académico, campo político, campo literario, campo artístico, etc (Bourdieu, 1990; Bourdieu, 2002; Bourdieu y Waqcuant, 2005; Baranger, 2012). Esa la apuesta teórica y metodológica de Bourdieu -conocida como estructuralismo constructivista-, recoge la tradición de las más importantes escuelas de la sociología, pues no se descarta que los determinantes estructurales demarcan a los sujetos, pero se reconoce que todo lo social es construido desde la lógica triple del constructivismo en cuanto a que la realidad existe, pero es construida y a su vez construye al ser humano (Berger y Luckmann, 1968). Bourdieu, Chamboredon y Passeron encuentran tres principios en los clásicos: 1) los sujetos sociales no tienen conciencia de lo que hacen -o principio de la no conciencia-, pues esa información la aportan las y los investigadores; 2) lo social es relacional y se lleva a cabo en un espacio social específico, principio del primado de la relación; 3) el conocimiento que se produce sobre lo social está mediado por lo que son las experiencias de investigadoras e investigadores, como principio del determinismo metodológico. Estos tres principios dan lugar a tres momentos respectivamente en el estructuralismo-constructivista de Bourdieu, en las categorías de habitus, campo y auto-socio-análisis (Bourdieu, Chamboredon y Passeron, 2002).
El campo, según Bourdieu, es el espacio social en el que tienen lugar las relaciones sociales, dentro de unas reglas internas propias, con un sentido compartido de pertenecer al campo (illusio), en el que los agentes sociales llevan a cabo prácticas sociales sobre todo para posicionarse mejor en el campo por medio de la acumulación de capitales, económico, cultural, social o simbólico, según sea el caso por la importancia del capital específico en cada campo y de acuerdo con ello, se pueden encontrar clases sociales, como cercanía de los agentes en el campo por el tipo y cantidad de capitales acumulados (Bourdieu, 1990, pp. 135141). Este se estudia desde una aproximación objetiva con datos estadísticos de agentes, capitales y posiciones, y desde una aproximación subjetiva, observando las prácticas sociales de los agentes, en lo que representa el mundo para ellos y las disposiciones, lo que permite hablar de los habitus y habitus de clase (Bourdieu, 1990; Gutiérrez, 2006). En el sociólogo francés cobra relevancia lo relacional en el campo, que diferencia su enfoque del estructural funcionalismo, pues el énfasis está en los seres humanos, sus luchas y su concepción de mundo, pero ubicados en una estructura como campo. Reconoce también, que el campo está ubicado histórico-culturalmente y tiene una trayectoria, en la que ha incidido la relación que se tiene con los otros campos, poniendo en juego su autonomía relativa y las luchas de los agentes, puesto que los agentes que se perciben como revolucionarios, heterodoxos o herejes, posibilitan cambios en las condiciones de juego de cada campo, frente a la ortodoxia que representa las normas, que generalmente benefician a los miembros más antiguos del campo.

Para el caso de las finanzas, sería necesario realizar investigaciones que construyan el campo financiero como herramienta de estudio, enten-

${ }^{5}$ Que concibe al sujeto como un receptor pasivo de lo que le transmite la cultura, en la que nace demarcando los aspectos estructurales con nulas posibilidades de generar cambio en su existencia pero tampoco en las condiciones de su sociedad ${ }^{6}$ En el que el sujeto, como habitus, puede cambiarse a sí mismo y, con ello, al mundo al que pertenece en el nivel más cercano en el que se encuentra inmerso 
dida en el sentido bourdiano, definiendo su lógica interna, condiciones de ingreso al campo en capital y conocimiento. La relación del campo financiero con los demás campos se percibe como una relación de subordinación del campo político, y con ello del social, frente al financiero; por ello es importante ubicar las posiciones de los agentes en el campo financiero, su sentido compartido, los capitales en juego y las luchas internas, al igual que las disposiciones de los agentes en sus prácticas sociales y con ello sus habitus.

Por ejemplo, en El lobo de Wall Street de Martin Scorsese (2013), se narra la vida del corredor de bolsa Jordan Belford que jugó el juego financiero con un profundo conocimiento práctico del campo, llegando a realizar movidas ilegales que pudieron sostenerse por años, llevando a la quiebra a sus inversionistas y enriqueciéndose él y sus compañeros. La película muestra prácticas sociales de los corredores de bolsa, sus gustos, aficiones, al igual que sus estrategias para acumulación de capital económico, pero también simbólico y social, aunque deja un sinsabor, al enviar un mensaje de admiración por haber logrado una fortuna en poco tiempo. Por el contrario, el mensaje de la película La gran apuesta de Adam McKay (2015) es de remordimiento y tristeza, pues el equipo de expertos financieros se enriquece con la crisis financiera que tuvo lugar en Estados Unidos entre 2007 a 2010, a partir de apostar en contra de la tendencia, adelantándose a lo que sería el desplome de la burbuja por poseer un conocimiento experto que les permitió visualizar con antelación lo que pasaba, pero al final los protagonistas no se regocijan con el dolor ajeno como Belford, a pesar de no devolver las ganancias obtenidas.

Por supuesto, resulta mejor la observación de agentes sociales en el campo financiero en Colombia, con el caso del Fondo Premium de Interbolsa (El Colombiano, 2014) y estrategias como la quiebra de la EPS Saludcoop (Rojas, Botero y Vega, 2016), entre otros casos, de manera que un análisis crítico de las finanzas desde Bourdieu pueda poner en evidencia el funcionamiento del campo financiero colombiano, y visibilizar las estrategias lícitas e ilícitas que se ponen en juego en el posicionamiento de los agentes que lo integran, puesto que las ciencias sociales poco se ocupan de realidades que son contundentes por su impacto social y económico, y que solamente se han dejado a periodistas y fiscales.

\section{La teoría crítica latinoamericana y la actividad financiera}

El empobrecimiento y la exclusión en Latinoamérica y el Caribe, han llevado a que diferentes investigadores de la filosofía y las ciencias sociales se hayan aglutinado en el enfoque de modernidad/colonialidad, o de(s)colonial, como uno de los enfoques críticos latinoamericanos más significativos en la actualidad y por el peso de su argumentación para develar la situación de esta región (Lander, 2000; Mignolo, 2005; Escobar, 2007 y Quijano, 2014), coincidiendo con regiones similares en África y Asia. Los planteamientos de estos autores se pueden resumir en tres esquemas de colonialidad en relación con el mundo occidental moderno. El primer tipo es la colonialidad del poder (Mignolo, 2005), que es el más evidente, que consiste en la autoridad que se adjudican los europeos, luego los norteamericanos y ahora los grandes inversionistas transnacionales, para apoderarse de las riquezas naturales, la mano de obra y el mercado, con recursos que van desde el establecimiento de la colonia hasta las nuevas formas de colonialismo, neoextractivismo y megaproyectos en la actualidad, de manera que la relación de nuestra región la ubica en un lugar subalterno (Villafuerte, 2014).

El segundo esquema de dominación es la colonialidad del ser (Quijano, 2014), figura que identifica el descubrimiento que hacen los europeos en el periodo de la colonia de la existencia de los otros, que les da autoridad para diferenciarse como superiores e imponer en los otros la forma de vida, pensamiento y organización que 
ellos tienen como la única y la mejor, es decir, reconocer la cultura occidental de la modernidad: el castellano, la religión católica, el pensamiento científico, lo que lleva de fondo la xenofobia, la exclusión, el uso del concepto raza en la colonia y las dificultades de ascenso social. La raza, como diferenciación social y sinónimo de inferioridad, y las políticas modernizadoras en países latinoamericanos en el siglo XIX y comienzos del XX continuaron con el exterminio de los grupos aborígenes y la anulación de lo tradicional, han generado sentimientos de inferioridad y actitudes subordinadas de menosprecio por lo autóctono.

El tercero, la colonialidad del saber (Lander, 2000), posiciona los conocimientos propios -indígenas, afro, mestizos, campesinos y popularescomo inferiores, con el argumento de que la modernidad está fundamentada en la razón; por tanto, lo que no sea eminentemente racional es inferior y no merece ser tenido en cuenta, pues carece de validez, hasta el punto de la destrucción física como el caso de los códices mayas en el periodo de la llamada conquista española, pero también la subvaloración permanente de lo que se ha denominado saberes, que se comparan con la ciencia para determinar que carecen de razón y de lógica.

Este grupo de autores críticos latinoamericanos devela la triple relación subalternizada de colonialidad del poder, del ser y del saber, que se vive en Latinoamérica y el Caribe, para posibilitar la salida del mundo que determinó la modernidad, que se aprecia sobre todo en la presente globalización neoliberal, en donde nuestra región ocupa un lugar de provisión de materias primas que, se depredan de manera extensiva en megaproyectos y neoextractivismo. Lo que se busca desde este enfoque es la posibilidad de pensar otros mundos posibles, fuera de la modernidad, fuera de la globalización, sin que esto implique necesariamente un retorno al indigenismo, sino la apertura a nuevas posibilidades, que puedan escapar de la relación de la triple colonialidad, tomando como base la inspiración en las sociedades no modernas y no occidentalizadas, que son las autóctonas, para las que el buen vivir en comunidad era una realidad y no la competitividad y el individualismo de la modernidad. Así, es imperativo buscar en lo indígena, lo afro, lo campesino y lo popular, fuentes de inspiración para salir de la modernidad.

Para el caso de las finanzas, se trataría de posibilitar unas finanzas populares, desde abajo, pero siendo consecuentes para que esto se diera en el nivel comunitario y no tanto para individuos determinados, generando fondos de ahorro e inversión comunitarios, al estilo del cooperativismo (Ressel, 2013), que se basa en los principios de economía solidaria (Álvarez, 2017). Abrir la mente a nuevas posibilidades no imaginadas hasta ahora, en donde todos ponen y todos reciben, todos contribuyen para la realización de proyectos comunitarios y familiares, y se pueda ir rotando a los beneficiarios. Igualmente, en figuras como los bancos de trueque (Pérez, 2003), que ponen a funcionar formas de economía basadas en lo indígena y campesino, donde los recursos económicos son superados por los talentos y habilidades de las personas que integran estas estrategias y lo que se intercambia puede ser un bien, pero sobre todo un servicio, mostrando que con o sin dinero se puede alcanzar un buen vivir con la generación de tejido social y apoyo mutuo. Finalmente, en ideas de subsistencia como las ecoaldeas y comunas (Salamanca y Silva, 2015), en las que grupos de personas de todas las procedencias comparten su espacio vital, conviviendo en un territorio en el que se vive y se produce desde el equilibrio de la naturaleza y el bien común, siendo coherentes también con los planteamientos que afirman que, ante todo se requiere estar en armonía con la madre naturaleza, apoyándose en la vida en comunidad -principios que se comparten también con el pensamiento rastafari (Larrañaga, 2008), el ecosocialismo (LeQuang y Vercoutere, 2013), la vida campesina e indígena. Eso sí, hay que cuidar de no caer en la estrategia mercantilista del capitalismo que subsume todos las intenciones críticas como parte del mercado, cuando en este caso la 
ecoaldea se ofrece como paquete turístico o como inversión, perdiendo la esencia de la vida en comunidad desde lo natural. La clave de estas iniciativas, y otras que puedan pensarse, es que sean desde abajo, a partir de la participación, tomando como punto de partida el buen vivir y no la acumulación de riqueza per se, posibilitando el empoderamiento de las comunidades para salir de la relación de dependencia con el Estado, mostrando el espíritu del paradigma sociocrítico en investigación que busca la transformación emancipatoria del mundo, y desde la iniciativa de las mismas comunidades, sin que se requiera de expertos ni políticos para generar la movilización.

\section{Conclusiones}

La intención de este artículo no fue dar fórmulas infalibles para posibilitar unas finanzas desde el paradigma socio-crítico; sino presentar planteamientos que abran el pensamiento a salidas alternativas desde la teoría crítica, el posestructuralismo y el pensamiento crítico latinoamericano, ante todo para abrir el debate considerando que las finanzas se han tomado generalmente como herramienta para favorecer la acumulación de grandes capitales en manos de los inversionistas más poderosos del planeta.

De acuerdo con los planteamientos revisados, la propuesta circula de la idea más radical en cuanto a la destrucción y desaparición de la actividad financiera como actividad que no genera productividad en los mercados reales, siendo especulativa en favor de quienes cuentan con el conocimiento y el capital, a pesar de que se publicite como democrática. De otra parte, la aceptación de unas finanzas más humanas en donde el conocimiento especializado no se quede como razón instrumental, sino que pueda acercarse a las comunidades, posibilitando pensar y crear estrategias de participación financiera de tipo comunitario, lo que requeriría de la participación de expertos que puedan compartir sus conocimientos pero en beneficio de las comunidades y no de los grandes inversionistas. Cercana a esta propuesta, puede plantearse otra similar que, desde abajo y de forma más participativa, va de la mano de economías que se encuentran funcionando exitosamente en países como Ecuador y Bolivia, en comunidades indígenas y campesinas a lo largo de Latinoamérica, como son la economía solidaria, cooperativa, del buen vivir, ecosocialismo, ecoaldeas, entre otras; que sin mayores pretensiones científicas actúan más y teorizan menos, sabiendo que si bien la economía solidaria es dinámica, se pueda incluir entre sus programas también el componente financiero.

Finalmente, se plantearon posibles programas de investigación desde Foucault, estudiando la discursividad de las finanzas que genera relaciones de dominación en el nivel estatal y de allí a todos los niveles. Al igual que un programa inspirado en Bourdieu, para realizar investigaciones que den cuenta de la actividad financiera vista como campo de las finanzas, indagando las luchas, posiciones, intereses, capitales y agentes, lo que puede permitir entre otras cosas, indagar por la ilegalidad en las finanzas cuando el conocimiento llega a ser tan especializado por parte de los financieros, que les hace generar estrategias y prácticas sin importar que rayen en lo delincuencial, como los cuatro casos mencionados a partir de los filmes y situaciones en Colombia, pues se prioriza la acumulación del capital económico sin importar las consecuencias propias y sociales.

Se espera entonces que, las ideas aquí expuestas sean útiles para encender el debate académico, pero sobre todo dar apertura a pensar las cosas establecidas, en esta caso las finanzas, de manera alternativa, máxime cuando estamos frente a formas de pensamiento y de hacer las cosas que legitiman y perpetúan la miseria y la injustica, y de lo que se trata el pensamiento crítico es de poner en tela de juicio ese orden de las cosas, para subvertirlo y buscar un mundo más justo. 


\section{Referencias bibliográficas}

Álvarez, J. (2017). Economía social y solidaria en el territorio: significantes y co-construcción de políticas públicas. Bogotá: Universidad Javeriana.

Baranger, D. (2012). Epistemología y metodología en la obra de Pierre Bourdieu. Posadas, Edición electrónica. Recuperado de http:// denisbaranger.blogspot.com.ar/

Berger, P. y Luckmann, T. (1968). La construcción social de la realidad. Buenos Aires: Amorrortu.

Bourdieu, P. (1990). Algunas propiedades de los campos. En: Sociología y cultura. México: Grijalbo.

(2007). El sentido práctico. Buenos Aires: Siglo XXI Editores.

Bourdieu, P., Chamboredon, J.C. y Passeron, J.C. (2002). El oficio del sociólogo. Presupuestos epistemológicos. Buenos Aires: Siglo XXI Editores.

Bourdieu, P. y Wacquant, L. (2005). Una invitación a la sociología reflexiva. Buenos Aires: Siglo XXI Editores.

Castro-Gómez, S. (2013). Michel Foucault y la Escuela de Frankfurt. Conferencia Seminario CES. Recuperado de https://www.youtube. $\mathrm{com} /$ watch?v=sMU2AbbTD00

Chacón, M. y Urrego, H. (2017). Pensar independiente: consideraciones para unas Finanzas desde el enfoque socio-crítico. Ponencia presentada en el XXI Congreso Internacional de Investigación en Ciencias Administrativas, ACACIA y UNIVA.

Deleuze, G. (2015). La subjetivación: curso sobre
Foucault (Tomo III). Buenos Aires: Cactus.

Escobar, A. (2007). La invención del tercer mundo. Construcción y deconstrucción del desarrollo. Caracas: Fundación Editorial El perro y la rana.

El Colombiano. (11 de agosto de 2014). Así fue el "tumbis" del Fondo Premium. Recuperado de https://www.asuntoslegales.com.co/actualidad/asi-fue-el-tumbis-del-fondo-premium-2155351

Foucault, M. (1988). El sujeto y el poder. En: Revista Mexicana de Sociología, 50 (3), Universidad Autónoma de México, pp. 3-20.

(1992). El orden del discurso. Buenos Aires: Tusquets Editores.

Gutiérrez, A (2006). Las Prácticas Sociales: Una Introducción a Pierre Bourdieu. Córdoba: Ferreyra Editor.

Horkheimer, M. (1973). Crítica de la razón instrumental. Buenos Aires: Editorial Sur.

Lander, E. (2000). La colonialidad del saber: eurocentrismo y ciencias sociales. Perspectivas latinoamericanas. Buenos Aires: Clacso.

Larrañaga, M. (2008). Notas sobre la espiritualidad rastafari. Espacio laical, 4. La Habana: Centro cultural Padre Felix Varela.

LeQuang, M. y Vercoutere, T. (2013). Ecosocialismo y buen vivir. Diálogo entre dos alternativas al capitalismo. Quito: Instituto de Altos Estudios Nacionales-

Marcuse, H. (1985). El hombre unidimensional. Ensayo sobre la ideología de la sociedad industrial avanzada. Barcelona: Planeta-Agostini.

Marx, K. (1845). Tesis sobre Feuerbach, Versión 
digital: http://www.ehu.eus/Jarriola/Docencia/EcoMarx/TESIS\%20SOBRE $\% 20$ FEUERBACH\%20Thesen\%20ueber\%20 Feuerbach.pdf

(1867). El capital. Tomo I. El proceso de producción del capital. México: Siglo XXI editores. Versión digital: http://www.enxarxa.com/biblioteca/MARX\%20El\%20Capital\%20-\%20Tomo\%20I.pdf

Marx, K. y Engels, F. (1848). Manifiesto del partido comunista. Versión digital: https://www. marxists.org/espanol/m-e/1840s/48-manif. htm

McKay, A. (2015). La gran apuesta. [Cinta cinematográfica]. Estados Unidos: Plan B Entertainment y Regency Enterprises.

Medialdea, B. \& Sanabria, A. (2013). La financiarización de la economía mundial: hacia una caracterización. En: Revista de Economía Mundial, №32. Madrid: Universidad Complutense de Madrid.

Mignolo, W. (2005). La idea de América Latina. La herida colonial y la opción decolonial. Barcelona: Gedisa.

Pérez, C. (2003). Trueque y economía solidaria. Buenos Aires: Clacso. Portal de Economía solidaria. https://www.economiasolidaria. org/taxonomy/term/3476

Quijano, A. (2014). Cuestiones y Horizontes. De la dependencia histórico-estructural a la colonialidad/descolonialidad del poder. Buenos Aires: Clacso. troducción al cooperativismo. Universidad Nacional de La Plata.

Ricoeur, P. (1970). Freud: una interpretación de la cultura. México: Siglo XXI Editores.

Rifa, M. (2003). Michel Foucault y el giro posestructuralista crítico feminista en la investigación educativa. Revista Educación y Pedagogía, XV (37).

Rojas, K.; Botero, L. y Vega, C. (9 de agosto de 2016). ¿Quién quebró realmente a Saludcoop? El Espectador. Versión digital: https://www.elespectador.com/noticias/nacional/quien-quebro-realmente-saludcooparticulo-648086

Salamanca, L. y Silva, D. (2015). El movimiento de ecoaldeas como experiencia alternativa de buen vivir. Polis Revista latinoamericana, 40. Osorno: Universidad de Los Lagos.

Sampaio, M. (2009). La Teoría Crítica de la Escuela de Francfort, de la primera a la tercera generación: un recorrido histórico. Revista Internacional de Filosofía Política, número 34. Madrid: UNED.

Scorsese, M. (2013). El lobo de Wall Street. [Cinta cinematográfica]. Estados Unidos: Paramount Pictures.

Stiglitz, J. (2002). El malestar en la globalización. Madrid: Punto de lectura.

Villafuerte, D. (2014). Neoextractivismo, megaproyectos y conflictividad en Guatemala y Nicaragua. Revista Espiral, XXI (61), Universidad de Guadalajara.

Ressel, A. (2013). Manual teórico práctico de in- Zuleta, E. (2005). Lógica y Crítica. Bogotá: Hombre Nuevo Editores. 